OPEN ACCESS

Edited by:

Qingxiang Meng,

Hohai University, China

Reviewed by:

Lei Lang,

Shanghai Jiao Tong University, China Zhipeng Xiang,

Yangtze River Scientific Research

Institute, China

${ }^{*}$ Correspondence:

Lehua Wang

lehuatg@126.com

Specialty section:

This article was submitted to

Interdisciplinary Physics,

a section of the journal

Frontiers in Physics

Received: 30 August 2021 Accepted: 27 September 2021 Published: 05 November 2021

Citation:

Duan G, Wang L, Deng H, Zhang J, Luo Z and Jiang Q (2021) Mechanical

Response of Listric Faults in the Three

Gorges Reservoir Area Based on

Three-Dimensional

Morphological Characteristics.

Front. Phys. 9:766920.

doi: 10.3389/fphy.2021.766920

\section{Mechanical Response of Listric Faults in the Three Gorges Reservoir Area Based on Three-Dimensional Morphological Characteristics}

\author{
Guoyong Duan ${ }^{1,2}$, Lehua Wang ${ }^{1,3 *}$, Huafeng Deng ${ }^{1,3}$, Jingyu Zhang ${ }^{1,4}$, Zuosen Luo ${ }^{1,3}$ and \\ Qiao Jiang ${ }^{5}$
}

${ }^{1}$ Key Laboratory of Geological Hazards on Three Gorges Reservoir Area (China Three Gorges University), Ministry of Education, Yichang, China, ${ }^{2}$ College of Electrical Engineering and New Energy, China Three Gorges University, Yichang, China, ${ }^{3}$ College of Civil Engineering and Architecture, China Three Gorges University, Yichang, China, ${ }^{4}$ College of Hydraulic and Environmental Engineering, China Three Gorges University, Yichang, China, ${ }^{5}$ China Three Gorges Construction Engineering Corporation, Chengdu, China

Faults or joints widely exist in rock masses, which deeply affect the mechanical properties of rock. The seismic frequency of the Gaoqiao fault and its surrounding areas in the Three Gorges Reservoir area before and after water storage is significantly higher than that in other areas. In this study, a curved joint is used to simulate the occurrence characteristics of the Gaoqiao fault, and the influence of reservoir water is simulated by adjusting the fracture water pressure. Compared with the changes of joint surface morphology parameters before and after the test, it is found that the macro failure characteristics of rock samples are in good agreement with the micromorphology changes of the joint surface. Among them, the parameters such as root-mean-square height $(\mathrm{Sq})$, arithmetic mean height $(\mathrm{Sa})$, reverse load area ratio (Smc), and minimum autocorrelation length (Sal) can better characterize the joint surface deterioration of rock samples under the action of fracture water pressure. The test results have a certain reference value for studying the fault response under the action of reservoir water.

Keywords: rock joints, microscopic morphological characteristics, fracture water pressure, macroscopic mechanical characteristics, curved joint

\section{INTRODUCTION}

Faults or joints are widespread in rock masses, and the mechanical characteristics of the rock masses vary with the environment in which they occur [1]. Especially, the mechanical response of faults or joints has a significant influence on the mechanical properties of the rock mass within the reservoir's influence range. In 1963, during the impounding of the Vajont Dam in Italy, rainstorms triggered the sliding of the left bank rock mass along the internal structural plane, with a volume of 240 million cubic meters, resulting in serious casualties and property losses [2-4]. On July 13, 2003, Qianjiangping Village, Zigui County of China, suffered a sudden decline of more than 15 million square meters, resulting in houses collapsing, plant destruction, traffic interruption, river blockage, and 24 deaths. According to the analysis of deformation traces, sliding process, and mechanical causes of the landslide, it was concluded that Qianjiangping landslide was a new-type, super-large, high-speed, deep bedding rock 
landslide of the reservoir which was mainly induced by reservoir impounding, combined with strong rainfall [5].

The existence of a rock mass interruption layer or joint in a reservoir area not only causes shallow geological disasters such as landslides but also induces a series of reservoir earthquake problems in the deep crust. The 1967 earthquake at the M6.5 reservoir at the Koyna Dam in India caused about 180 deaths [6-8]. Similarly, the 1966 M6.3 reservoir earthquake at Kremasta reservoir in Greece [9], the 1963 M6.1 reservoir earthquake at Kariba reservoir in Zambia-Zimbabwe [10, 11], and the 1962 M6.1 reservoir earthquake at Xinfengjiang reservoir in China [12] are also included. Seismologists mainly study from the perspective of seismology, focusing on the study of specific seismic parameters such as focal depth, corner frequency, seismic moment, seismic energy, apparent stress, fractal dimension, and b value [13-17]. Hydraulic fracturing technology commonly used in the field of energy exploitation may also produce similar induced seismic effects $[18,19]$.

Therefore, the study of the mechanical response of joint surface under natural water provides a new idea for studying geological disasters and reservoir earthquakes in reservoir areas. Previous studies have shown that the mechanical properties of compression and shear of jointed rock masses deteriorate under the action of water $[20,21]$. The seismogenic fault of reservoir earthquakes is generally affected by groundwater, in-situ stress, and other factors. The porosity, pore geometry [22], and fracture surface [23] of different types of rock masses are different. Coupled with the changes in the groundwater storage environment (such as fracture water pressure), the pore water pressure in rocks shows great differences.

However, most of the above studies only consider the variation of joint shape and fracture water pressure. The deep rock mass in the reservoir area is also affected by water pressure at the fracture surface and pore water pressure, which makes its mechanical properties more complex. Furthermore, in the laboratory test of rock mechanics, most studies mainly generalize the natural joints as linear or plane joints [24-27], and the occurrence form is through joints or non-through joints. However, in the process of actual geological structure evolution, different strata and faults are mostly curved surfaces from a macro point of view.

In this study, immersion saturation of rock mass with listric fault in the reservoir area and crack water pressure are considered. Triaxial compression tests of dry and saturated rock samples were carried out by simulating the listric fault structure with curved joints in the samples. At the same time, different fracture water pressures are applied to the fractured surface of rock samples to simulate the dry and wet state of rock mass during impounding. By comparing the changes of threedimensional morphological parameters of the joint surface before and after the test, the morphological parameters which can characterize the variation of joint surface are screened out, and the three-dimensional morphological changes of the joint surface under different conditions are studied by combining the strength and failure characteristics. The test results can provide some reference for mechanical response research of listric fault structure in the reservoir area.

\section{EXPERIMENT}

\section{Sample Preparation and Experimental Apparatuses}

The rock samples are taken from the Gaoqiao fault area where earthquakes are more frequent in the Three Gorges Reservoir area and where the Triassic Jialingjiang Formation thick limestone is widely distributed. From the perspective of the geological structure, the Gaoqiao fault is larger in the Badong section of the Three Gorges Reservoir area, which has the conditions to "trigger" structural reservoir earthquakes. According to the rock outcrops in this area (Figure 1), the rock inclination angle is from steep to gentle, about $20^{\circ}-40^{\circ}$. The preparation method is to first drill and core the rock blocks retrieved on-site and then perform joint cutting with a water jet, and finally obtain a rock sample with curved joints. The permeable hole at the bottom of the rock sample is used to exert fracture water pressure on the joint surface.

The French Top Industrie rock triaxial tester is used for the triaxial stress-fracture hydraulic coupling test, and the ST500 three-dimensional noncontact surface profiler is used for the study of the microscopic characteristics of the joint surface (Figure 2).

The basic physical and mechanical parameters of the complete rock sample obtained through the triaxial test are shown in Table 1.

In the triaxial compression test, when the confining pressure is $5,10,15,20$, and $25 \mathrm{MPa}$, the corresponding triaxial compressive strength is $169.22,194.02,234.76,271.53$, and $307.73 \mathrm{MPa}$, respectively. According to the fitting formula of triaxial compressive strength under different confining pressures, the uniaxial compressive strength is $129 \mathrm{MPa}$.

\section{Test Method}

According to the stress conditions of rock mass in the study area, in the triaxial test, the initial axial pressure is $100 \mathrm{MPa}$ and the confining pressure is $50 \mathrm{MPa}$. The rock samples in dry and saturated states are selected, respectively, to simulate the rock mass state before and after water storage. After reaching the initial stress state, different water pressures $(0,5,10$, and $20 \mathrm{MPa}$ ) are applied to the fracture surface through the permeable hole at the bottom of the rock sample. During the test, the loading rate of axial pressure, confining pressure, and the water pressure remains constant. In the test, the axial pressure loading rate is $2 \mathrm{MPa} / \mathrm{min}$, the confining pressure loading rate is $1 \mathrm{MPa} / \mathrm{min}$, and the hydraulic loading rate is $1 \mathrm{MPa} / \mathrm{min}$. When the water pressure reaches the predetermined value, it needs to be maintained for $30 \mathrm{~min}$ to ensure that the water pressure is evenly distributed on the fracture surface. After the water pressure is maintained for $30 \mathrm{~min}$, the axial pressure is applied continuously until the sample is damaged.

Through the triaxial compression tests of dry and saturated jointed rock samples under different fracture water pressures, the alternation of three-dimensional morphology parameters and macro-mechanical properties of the joint surface before and after the test are compared, and the correlation between the 


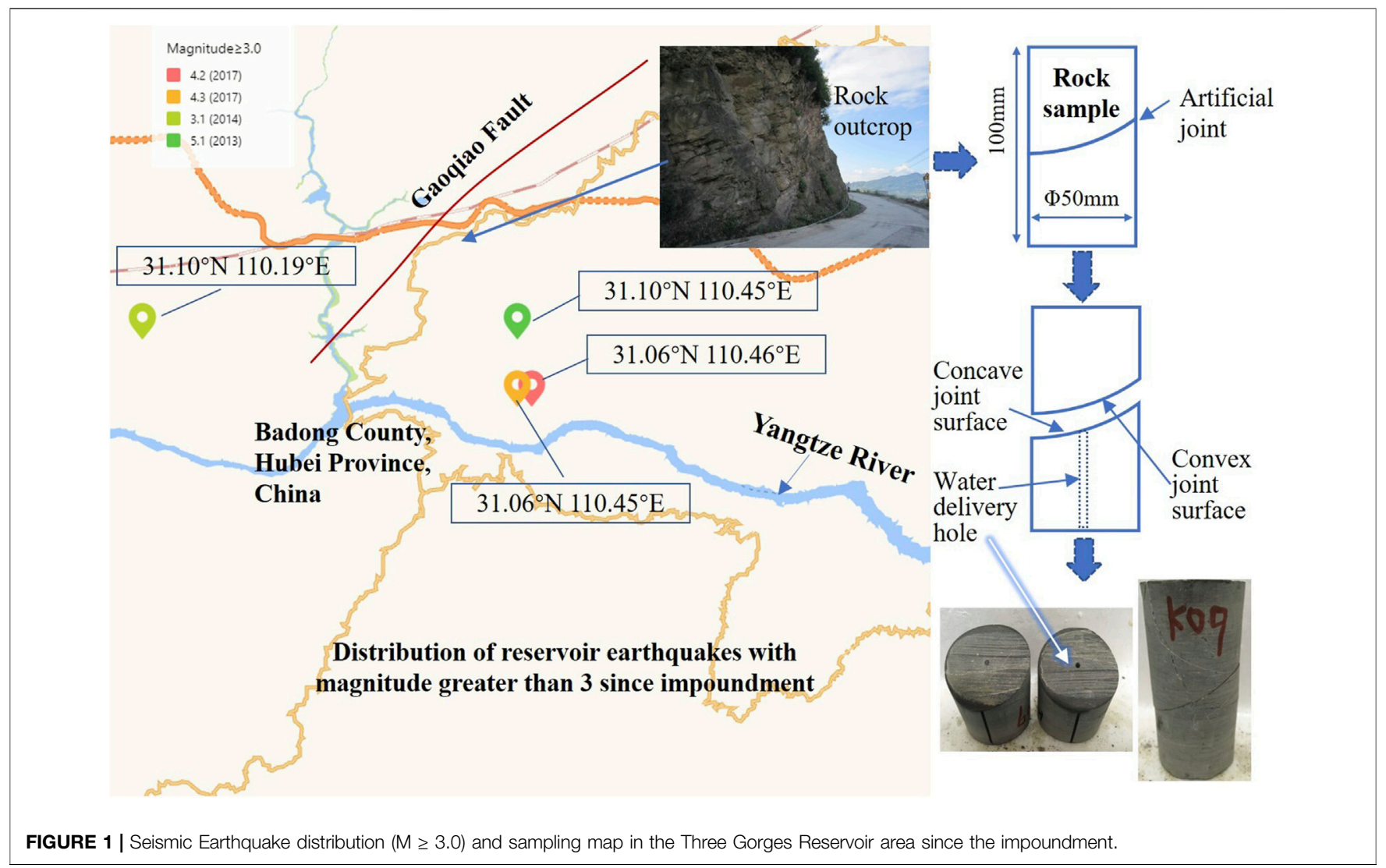

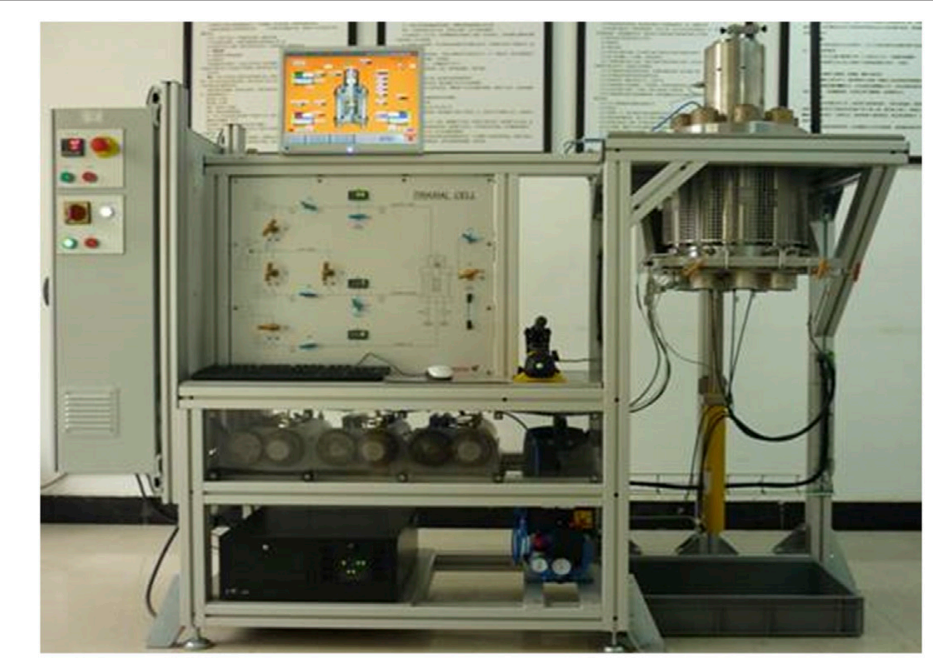

TOP INDUSTRIE rock triaxial tester
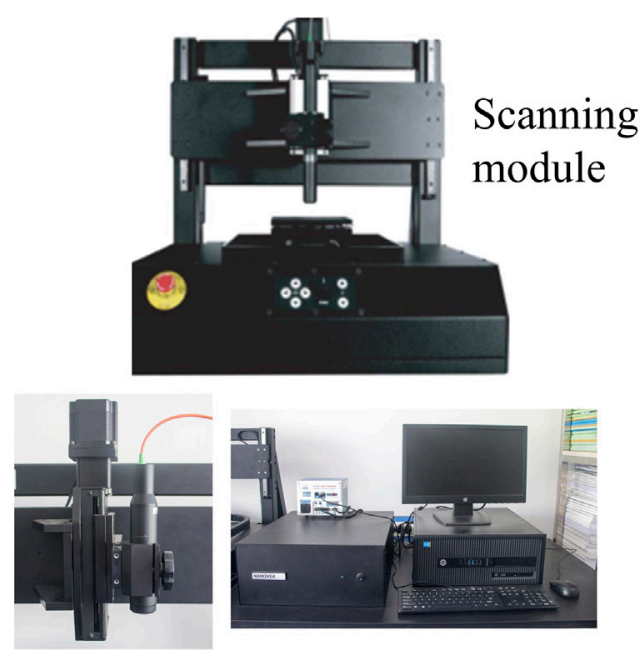

Light source Control module

ST500 three-dimensional non-contact surface profiler

FIGURE 2 | Test instruments. 
TABLE 1 | Basic physical and mechanical parameters of the rock sample.

\begin{tabular}{|c|c|c|c|c|c|c|}
\hline Parameters & Density $\left(\mathrm{g} / \mathrm{cm}^{3}\right)$ & $\begin{array}{c}\text { Elastic Modulus } \\
\text { (GPa) }\end{array}$ & $\begin{array}{l}\text { Deformation Modulus } \\
\text { (GPa) }\end{array}$ & Cohesion (MPa) & $\begin{array}{c}\text { Internal Friction } \\
\text { Angle }\left({ }^{\circ}\right)\end{array}$ & $\begin{array}{c}\text { Tensile Strength } \\
\text { (MPa) }\end{array}$ \\
\hline Value & 2.69 & 45.59 & 48.89 & 22.27 & 50.28 & 6.05 \\
\hline
\end{tabular}

TABLE 2 | Definitions of three-dimensional morphological parameters.

\begin{tabular}{|c|c|c|}
\hline Symbols & Name & Definition \\
\hline $\mathrm{Sq}$ & RMS height & $\begin{array}{l}\text { The standard deviation of the height distribution or RMS surface roughness. Computes the standard deviation for the } \\
\text { amplitudes of the surface }\end{array}$ \\
\hline $\mathrm{Sa}$ & Arithmetical mean height & Mean surface roughness \\
\hline Smc & Inverse areal material ratio & Height $c$ at which a given areal material ratio $p$ is satisfied. The height is calculated from the mean plane \\
\hline Sal & Autocorrelation length & $\begin{array}{l}\text { The horizontal distance of the autocorrelation function (tx, ty) has the fastest decay to a specified value } s \text {, with } 0<s<1 \text {. The } \\
\text { default value for } s \text { in the software is } 0.2 \\
\text { This parameter expresses the content in the wavelength of the surface. A high value indicates that the surface has mainly } \\
\text { high wavelengths (low frequencies) }\end{array}$ \\
\hline
\end{tabular}

RMS, root mean square.

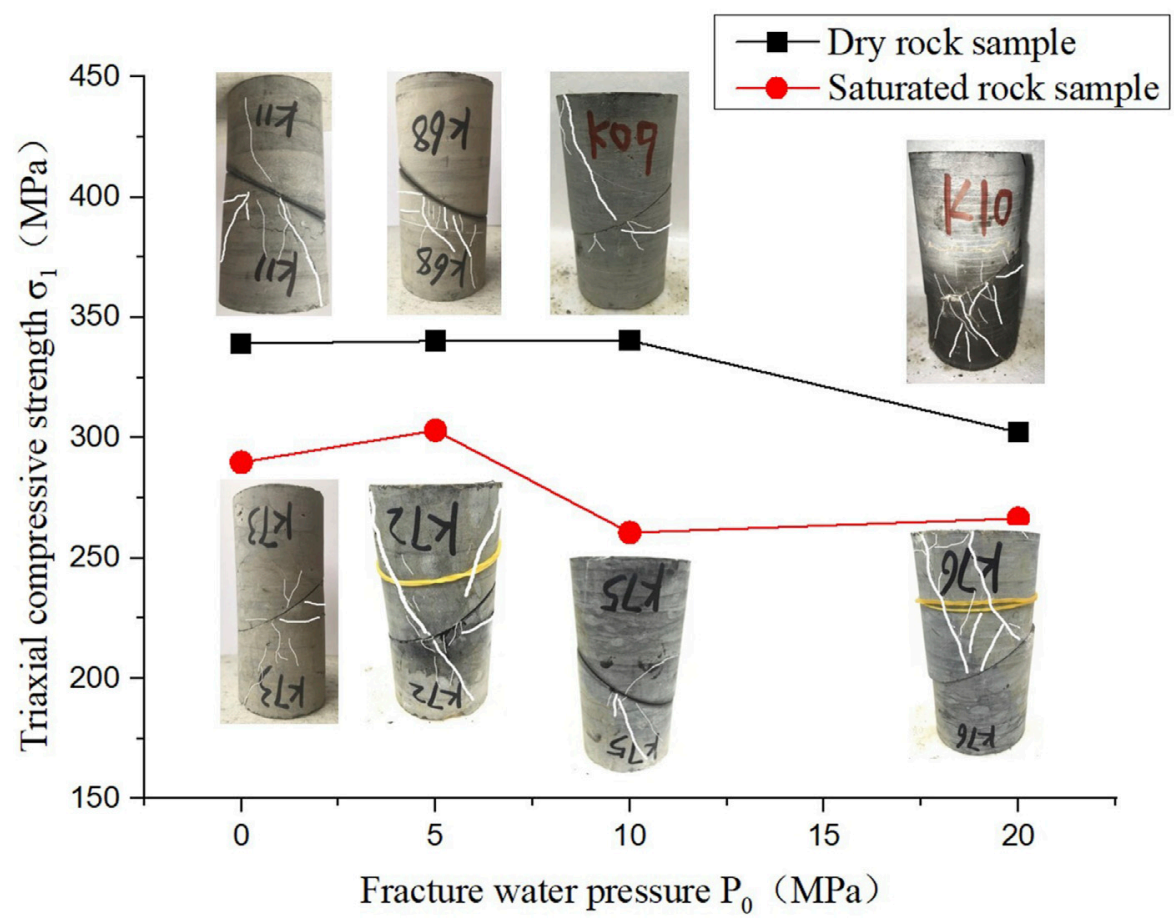

FIGURE 3 | Strength and failure characteristics of dry and saturated samples (Thick white lines represent the principal cracks and the thin white lines represent the secondary cracks).

morphology parameters of the joint surface and the mechanical properties of rock mass is studied.

\section{Three-dimensional Surface Texture Parameters}

On the upper and lower parts of the contact surface (joint surface) of the rock sample, there are complex shapes with different heights, depths, and gaps. Among them, the small spacing and the unevenness of the small peaks and valleys on the surface are called surface roughness. During the loading process, the upper and lower parts of the rock sample will inevitably have frictional slippage on the contact surface (joint surface). Therefore, observation and analysis of the microscopic morphology parameters (surface roughness) of the joint surface before and after the test is helpful for the comprehensive analysis of the rock 
TABLE 3 | The change rate of morphological parameters of dry rock samples (\%).

\begin{tabular}{|c|c|c|c|c|c|c|c|c|}
\hline $\begin{array}{l}\text { Fracture } \\
\text { Water } \\
\text { Pressure }\end{array}$ & $0 \mathrm{MPa}$ & $5 \mathrm{MPa}$ & $10 \mathrm{MPa}$ & $20 \mathrm{MPa}$ & $0 \mathrm{MPa}$ & $5 \mathrm{MPa}$ & $10 \mathrm{MPa}$ & $20 \mathrm{MPa}$ \\
\hline Parameters & \multicolumn{4}{|c|}{ Concave joint surface } & \multicolumn{4}{|c|}{ Convex joint surface } \\
\hline $\mathrm{Sq}$ & 31.88 & -34.02 & -0.62 & -8.90 & -14.80 & -35.77 & 4.19 & -13.88 \\
\hline $\mathrm{Sa}$ & -6.22 & -30.04 & 14.83 & 3.27 & -13.00 & -31.65 & 6.22 & -11.65 \\
\hline Smc & -11.44 & -29.05 & 18.38 & -16.60 & -16.05 & -41.29 & -7.45 & 4.02 \\
\hline Sal & -4.78 & -5.71 & -0.03 & -9.31 & 1.66 & 0.72 & 1.31 & -0.87 \\
\hline
\end{tabular}

TABLE 4 | The change rate of morphological parameters of saturated rock samples (\%).

\begin{tabular}{|c|c|c|c|c|c|c|c|c|}
\hline $\begin{array}{l}\text { Fracture } \\
\text { Water } \\
\text { Pressure }\end{array}$ & $0 \mathrm{MPa}$ & $5 \mathrm{MPa}$ & $10 \mathrm{MPa}$ & $20 \mathrm{MPa}$ & $0 \mathrm{MPa}$ & $5 \mathrm{MPa}$ & $10 \mathrm{MPa}$ & $20 \mathrm{MPa}$ \\
\hline Parameters & \multicolumn{4}{|c|}{ Concave joint surface } & \multicolumn{4}{|c|}{ Convex joint surface } \\
\hline $\mathrm{Sq}$ & 0.21 & 4.99 & 75.30 & 1.29 & -24.06 & -18.77 & -7.87 & -2.87 \\
\hline $\mathrm{Sa}$ & 3.78 & 2.59 & 67.57 & 9.20 & -20.11 & -14.16 & -6.37 & -0.61 \\
\hline Smc & 3.48 & -8.35 & 46.55 & 18.90 & -29.41 & -7.54 & -5.26 & 2.79 \\
\hline Sal & -0.24 & -3.62 & -9.52 & 4.35 & 0.40 & -6.44 & 1.73 & -2.86 \\
\hline
\end{tabular}

sample-the changing characteristics of joint surfaces in the destruction process and the impact of changes in the external environment can also be explored through microscopic morphology parameters. Since the joint surface of the rock sample is a curved surface arranged obliquely, to better collect the morphological features, the angle between the axis of the sample and the normal of the horizontal plane is maintained at $30^{\circ}$ during scanning. According to the geometric characteristics of the joint surface, the root-mean-square height (Sq), arithmetic average height $(\mathrm{Sa})$, reverse load area ratio $(\mathrm{Smc})$, and minimum autocorrelation length (Sal) are selected as the main analysis parameters.

The parameter formulae definitions are shown in Table 2.

\section{CORRELATION ANALYSIS OF MACROSCOPIC MECHANICAL CHARACTERISTICS AND THREE- DIMENSIONAL MORPHOLOGICAL CHARACTERISTICS}

It can be seen from Figure 3 that the triaxial compressive strength of the dry sample is greater than that of the saturated sample under different fracture water pressures. It shows that the saturation state degrades the strength of the jointed rock mass. For dry rock samples, when the fracture water pressure is low, the strength deterioration is not obvious, and when the fracture water pressure rises to $20 \mathrm{MPa}$, the strength decreases significantly. According to the available data, the depth of the reservoir earthquake in the Three Gorges Reservoir area is 4-10 km. Without considering the excess pore water pressure, the hydrostatic pressure of the magnitude depth of the reservoir earthquake will reach 40-100 $\mathrm{MPa}$. Obviously, under the condition of reservoir water storage, the deterioration of the mechanical properties of seismogenic faults is inevitable.

According to the distribution of cracks when the specimen is a failure, when the fracture water pressure is low, a single through crack appears and a few secondary cracks distributed along the joint plane appear; when the fracture water pressure is higher, multiple through cracks and secondary cracks appear. It can be inferred from this that the specimens under low water pressure are dominated by compression-shear failure. With the gradual increase of water pressure, the failure mode turns to slide shear failure along the joint plane. The changes of the morphological characteristic parameters indicate that the morphological characteristics of the joint surface are closely related to the failure form of the sample. The change rate of surface topography parameters is shown in Tables 3, 4. The variation trend of each parameter is shown in Figure 4.

Based on the change rate of topography parameters, it can be concluded that the wear degree of concave and convex surfaces along the curved joints is different.

The alteration of Sq is used to characterize the degree of dispersion of the height of each point. The Sq value of the dried sample under the condition of lower water pressure changes greatly, indicating that the frictional damage of the joint surface under pressure is more significant on the dried sample. The Sq values of the concave surface of the saturated samples all increase, while the Sq value of the convex surface decreases, indicating that the damage degree of the concave surface is greater than that of the convex surface.

Another spatial parameter $\mathrm{Sa}$ is used to characterize the arithmetic average height of each point on the surface. For dry samples, the changing trends of the concave and convex surfaces of the joint surface are almost opposite. Even when the surface is 


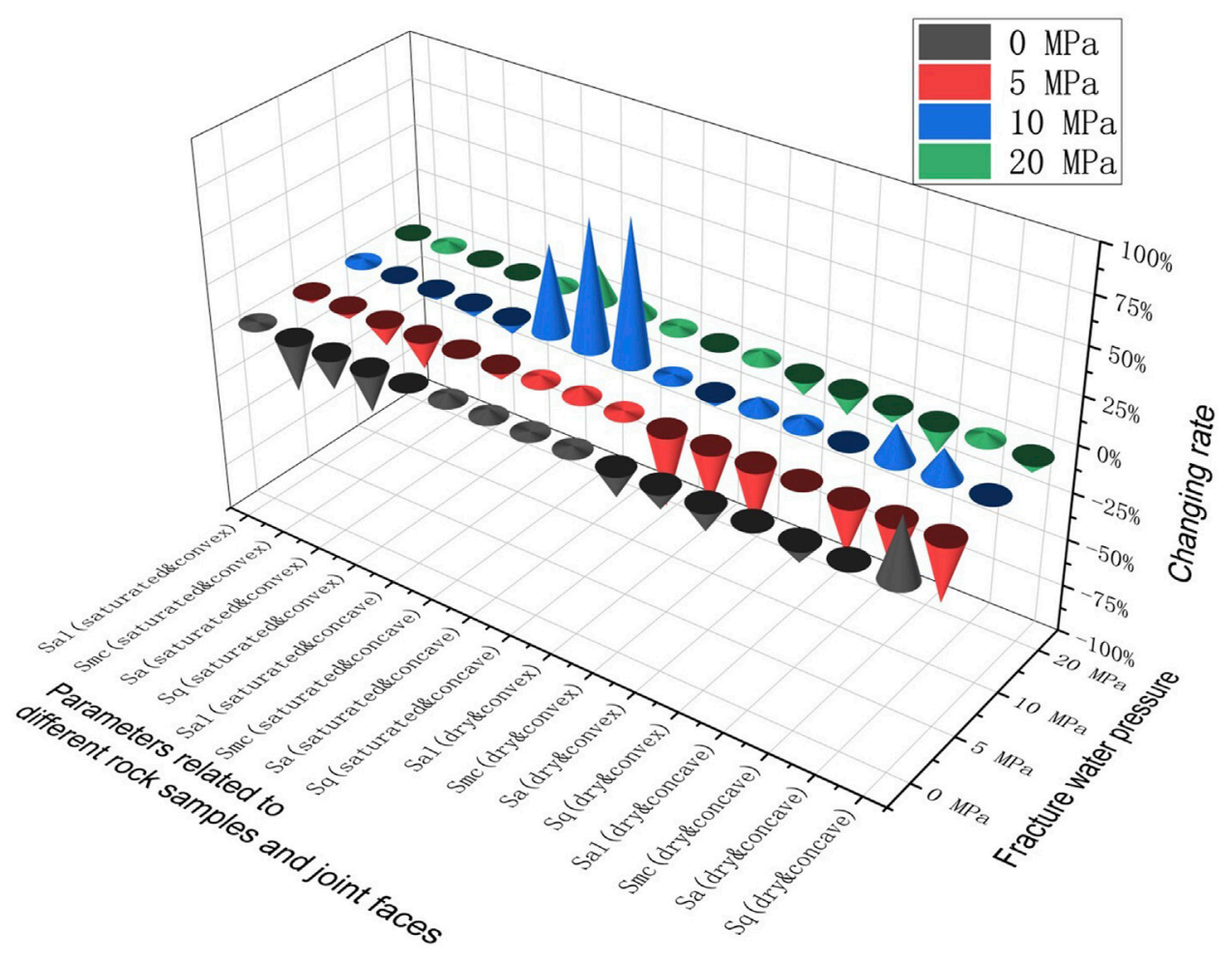

FIGURE 4 | Comparison of the change rates of morphological parameters with different samples and joint surfaces.

worn, the roughness of the concave surface is still greater than that of the convex surface.

A functional parameter Smc is used to characterize the change in smoothness of the joint surface, and the decrease of the parameter indicates the decrease of the surface roughness. The Smc values of the concave and convex surfaces on the joint surface of the dried sample under different water pressures mainly showed a decreasing trend, indicating that the slippage of the sample along the joint surface would reduce the roughness of the joint surface. The increase of the Smc value of the concave surface of the saturated sample is related to the change of the surface morphology caused by the formation of secondary cracks.

The Sal, a spatial parameter, is an autocorrelation function. According to the profile variation of the measured surface, Sal represents the overlap between the height data after offset and the height data itself. If the offset is small, the overlap portion is large, so the autocorrelation also becomes large. If the offset is large, the overlap portion is small, so the autocorrelation also becomes small. The changes of the Sal value under different samples and different water pressures are all within $10 \%$, indicating that the relative deviation of the upper and lower parts of the rock sample is relatively small on the whole.

It can be inferred from the various characteristics of the above joint surface that under the joint action of external load and water, more failure cracks will appear in the lower half of the fault, to form more reservoir water infiltration channels, which may induce deeper earthquakes. According to the variation trend of parameter Sal, the relative slip of the upper and lower surfaces of the seismogenic fault should be within $10 \%$, so multiple earthquakes may occur in the same area.

\section{CONCLUSION}

The rock mass containing curved fault structures in the reservoir area is affected by water storage, and its mechanical properties are degraded. Through the triaxial compression test, the article considers the effects of dry and saturated conditions and the water pressure of different fracture surfaces, combined with the failure characteristics of the sample, and analyzes the degree of change of the topography parameters on the joint surface. It is concluded as follows:

For curved joints, under pressure, the adjacent surfaces contacted by the joint have different degrees of wear.

The morphology change of the joint surface is affected by the main failure mode of the sample, and the wear degree of the dry sample is greater than that of the saturated sample.

The convex surface of the saturated sample shows a trend of decreasing surface morphology with the increase of the fracture water pressure, indicating that water has a certain lubrication effect on the joint surface, and the greater the water pressure, the more significant the lubrication effect.

For dry rock samples, the lubrication effect of fracture water pressure is not obvious. It is because the fissure water partially acts on the saturation process, and the lubrication effect on the joint surface is weakened. 
The test results reveal the trend that reservoir earthquakes extend to the deep and occur repeatedly in the same area.

\section{DATA AVAILABILITY STATEMENT}

The original contributions presented in the study are included in the article/Supplementary Material, and further inquiries can be directed to the corresponding authors.

\section{AUTHOR CONTRIBUTIONS}

All authors contribute equally.

\section{FUNDING}

This work was supported by Open Fund of Key Laboratory of Geological Hazards on Three Gorges Reservoir Area (China

\section{REFERENCES}

1. Cook NGW. Natural Joints in Rock: Mechanical, Hydraulic and Seismic Behaviour and Properties Under Normal Stress. Int J Rock Mech Mining Sci Geomechanics Abstr (1992) 29(3):198-223. doi:10.1016/0148-9062(92) 93656-5

2. Alonso EE, Pinyol NM. Criteria for Rapid Sliding I. A Review of Vaiont Case[. J Eng Geology (2010) 114(3-4):198-210. doi:10.1016/j.enggeo.2010.04.018

3. Pinyol NM, Alonso EE. Criteria for Rapid Sliding II.: Thermo-HydroMechanical and Scale Effects in Vaiont Case[J]. Eng Geology (2010) 114(34):211-27. doi:10.1016/j.enggeo.2010.04.017

4. Hendron AJ, Patton FD. The Vaiont Slide. A Geotechnical Analysis Based on New Geologic Observations of the Failure Surface. Volume 1. Main Text[J]. Eng Geology (1987) 24(1-4):475-91. doi:10.1016/0013-7952(87)90080-9

5. Wen B, Jian S, Tan J. Evaluation of the Roles of Reservoir Impoundment and Rainfall for the Qianjiangping Landslide in Zigui County, Three Gorges Area. In: F Wang $\mathrm{T}$ Li, editors. Landslide Disaster Mitigation in Three Gorges Reservoir. China: Springer Berlin Heidelberg (2009). doi:10.1007/978-3-64200132-1_9

6. Yadav A, Bansal BK, Pandey AP. Five Decades of Triggered Earthquakes in Koyna-Warna Region, Western India - A Review. Earth-Science Rev (2016) 162:433-50. doi:10.1016/j.earscirev.2016.09.013

7. Gupta HK, Arora K, Purnachandra Rao N, Roy S, Tiwari VM, Patro PK, et al. Investigations of Continued Reservoir Triggered Seismicity at Koyna, India. Geol Soc Lond Spec Publications (2017) 445(1):151-88. doi:10.1144/sp445.11

8. Gupta HK, Shashidhar D, Mahato CR, Satyanarayana HVS, Mallika K, Purnachandra Rao N, et al. Location of the Pilot Borehole for Investigations of Reservoir Triggered Seismicity at Koyna, India. Gondwana Res (2017) 42:133-9. doi:10.1016/j.gr.2016.10.014

9. Kilias AA, Tranos MD, Papadimitriou EE, Karakostas VG. The Recent Crustal Deformation of the Hellenic Orogen in Central Greece; the Kremasta and Sperchios Fault Systems and Their Relationship with the Adjacent Large Structural Features. $z \operatorname{dgg}$ (2008) 159(3):533-47. doi:10.1127/1860-1804/2008/ 0159-0533

10. Magadza C. Kariba Reservoir: Experience and Lessons Learned. Lakes Reservoirs Res Management (2010) 11(4):271-86. doi:10.1111/j.1440-1770.2006.00308.x

11. Gough DI, Gough WI. Stress and Deflection in the Lithosphere Near Lake Kariba?I. Geophys J Int (1970) 21(1):65-78. doi:10.1111/j.1365246x.1970.tb01767.x

12. Shen L-Y, Chang B-Q. Application of Stress-Pore Pressure Coupling Theory for Porous Media to the Xinfengjiang Reservoir Earthquakes. Pageoph (1995) 145(1):123-37. doi:10.1007/bf00879488
Three Gorges University), Ministry of Education (Grant No. 2020KDZ12), the National Nature Science Foundation of China (Grant No. 52009067), China National Natural Science Foundation Joint Funded Project (No. U1965109), and Hubei Provincial Natural Science Foundation Innovation Group Project (No. 2020CFA049).

\section{ACKNOWLEDGMENTS}

The authors gratefully acknowledge the financial support by Open Fund of Key Laboratory of Geological Hazards on Three Gorges Reservoir Area (China Three Gorges University), Ministry of Education (Grant No. 2020KDZ12), the National Nature Science Foundation of China (Grant No. 52009067), China National Natural Science Foundation Joint Funded Project (No. U1965109), Hubei Provincial Natural Science Foundation Innovation Group Project (No. 2020CFA049).

13. Apostol BF. The Inverse Problem in Seismology. Seismic Moment and Energy of Earthquakes. Seismic hyperbola. arXiv preprint arXiv:1808.03049 (2018).

14. Jian W, Jiankuan X, Xiaofei C. The Relations Between the Corner Frequency, Seismic Moment and Source Dynamic Parameters Derived from the Spontaneous Rupture of a Circular Fault. Geophys J Int (2021) 228(1): 134-46. doi:10.1093/gji/ggab346

15. Zhang Z, Lisheng XU, Hailin DU. M_W8.2 Fiji Deep Earthquake: HighFrequency Radiation Process and Seismic Genesis. Chin J Geophys (2018) 62(11):4279-89. doi:10.6038/cjg2019M0629

16. Butcher A, Luckett R, Kendall JM, Baptie B. Seismic Magnitudes, Corner Frequencies, and Microseismicity: Using Ambient Noise to Correct for HighFrequency Attenuation. Bull Seismological Soc America (2020) 110(3): 1260-75. doi:10.1785/0120190032

17. Spallarossa D, Picozzi M, Scafidi D, Morasca P, Turino C., Bindi D. The RAMONES Service for Rapid Assessment of Seismic Moment and Radiated Energy in Central Italy: Concepts, Capabilities, and Future Perspectives. Seismological Res Lett (2021) 92(3):1759-72. doi:10.1785/0220200348

18. Wasantha PLP, Konietzky H, Weber F. Geometric Nature of Hydraulic Fracture Propagation in Naturally-Fractured Reservoirs. Comput Geotechnics (2017) 83:209-20. doi:10.1016/j.compgeo.2016.11.005

19. Johnson LR, Majer EL. Induced and Triggered Earthquakes at the Geysers Geothermal Reservoir. Geophys J Int (2017) 209(2):1221-38. doi:10.1093/gji/ ggx082

20. Deng HF, Qi Y, Li JL. Degradation Mechanism of Intermittent Jointed Sandstone Under Water-Rock Interaction. Chinese J Geotechnical Eng (2021) 43(4):634-43. doi:10.11779/CJGE202104005

21. Yao W, Li C, Zhan H, Zhou J-Q, Criss RE, Xiong S, et al. Multiscale Study of Physical and Mechanical Properties of Sandstone in Three Gorges Reservoir Region Subjected to Cyclic Wetting-Drying of Yangtze River Water. Rock Mech Rock Eng (2020) 53(5):2215-31. doi:10.1007/s00603-019-02037-7

22. Aliakbardoust E, Rahimpour-Bonab H. Effects of Pore Geometry and Rock Properties on Water Saturation of a Carbonate Reservoir. Journal Petroleum Science Engineering. (2013) 112:296-309. doi:10.1016/j.petrol.2013.11.018

23. Abbasi S, Tavakkolian M, Shahrabadi A. An Experimental Study of the Effect of the Water Injection Process on Rock Structure and Permeability Reduction. Petroleum Science Technology. (2012) 30(7):685-98. doi:10.1080/ 10916466.2010.490808

24. Shu PY, Li HH, Wang TT, Ueng TH. Dynamic Strength of Rock with Single Planar Joint under Various Loading Rates at Various Angles of Loads Applied. J Rock Mech Geotechnical Eng (2018) 10(3):545-54. doi:10.1016/j.jrmge.2018.01.005

25. Ghazvinian A, Nejati HR, Sarfarazi V, Hadei MR. Mixed Mode Crack Propagation in Low Brittle Rock-like Materials. Arab J Geosci (2013) 6(11): 4435-44. doi:10.1007/s12517-012-0681-8 
26. Sarfarazi V, Ghazvinian A, Schubert W, Blumel M, Nejati HR. Numerical Simulation of the Process of Fracture of Echelon Rock Joints. Rock Mech Rock Eng (2014) 47(4):1355-71. doi:10.1007/s00603-013-0450-3

27. Yin DW, Chen SJ, Chen B, Liu XQ, Ma HF. Strength and Failure Characteristics of the Rock-Coal Combined Body with Single Joint in Coal. Geomechanics Eng (2018) 15(5): 1113-24. doi:10.12989/gae.2018.15.5.1113

Conflict of Interest: Author QJ is employed by China Three Gorges Construction Engineering Corporation.

The remaining authors declare that the research was conducted in the absence of any commercial or financial relationships that could be construed as a potential conflict of interest.
Publisher's Note: All claims expressed in this article are solely those of the authors and do not necessarily represent those of their affiliated organizations, or those of the publisher, the editors, and the reviewers. Any product that may be evaluated in this article, or claim that may be made by its manufacturer, is not guaranteed or endorsed by the publisher.

Copyright $\odot 2021$ Duan, Wang, Deng, Zhang, Luo and Jiang. This is an open-access article distributed under the terms of the Creative Commons Attribution License (CC $B Y$ ). The use, distribution or reproduction in other forums is permitted, provided the original author(s) and the copyright owner(s) are credited and that the original publication in this journal is cited, in accordance with accepted academic practice. No use, distribution or reproduction is permitted which does not comply with these terms. 